\title{
O Laboratório de Educação Matemática e a Formação Inicial de Professores de Matemática
}

The Laboratory of Mathematical Education and the Initial Training of Mathematics Teachers

El Laboratorio de Educación Matemática y la Formación Inicial de Maestros de Matemáticas

\section{AMÉRICO JUNIOR NUNES DA SILVA ${ }^{1}$}

${ }^{1}$ Universidade do Estado da Bahia

\begin{abstract}
RESUMO: Este artigo é resultado de uma pesquisa qualitativa do tipo estudo de caso que objetivon compreender quais as concepcões que estudantes de um curso de licenciatura em Matemática apresentam, em seu último semestre do curso, em relação ao Laboratório de Educação Matemática (LEM) e as implicações do mesmo para as suas formações e futura prática profissional. Para produção de dados utilizou-se um questionário, com questões abertas, que foram analisadas pela Análise de Conteúdo, referenciando-se, sobretudo, em Bardin (2009). Para a fundamentação teórica buscou-se autores que discutem formação de professores, principalmente, dos que ensinam Matemática, ludicidade e o LEM, em suas diferentes perspectivas, foram eles: Brougère (2002), Gatti (2019), Shulman (2005), Lorenzato (2010), Silva (2014, 2020a, 2020b), Cury (2011) e Alves (2001). A pesquisa sinalizou um reconbecimento do LEM enquanto espaço importante para a formação inicial e futura prática docente. No entanto, aos participantes da pesquisa, não se garantiu vivências nesse espaço durante a licenciatura.
\end{abstract}

Concepções. Formação de Professores. Laboratório de Educação Matemática. Licenciatura em Matemática.

\begin{abstract}
This article is the result of a qualitative research of the case study type which aimed to understand what conceptions that students of a Mathematics Degree course present, in their last semester of the course, in relation to the Mathematics Education Laboratory (LEM) and its implications for their training and future professional practice. For data production, a questionnaire was used, with open questions, which were analyzed by Content Analysis, referring, above all, to Bardin (2009). For the theoretical foundation, authors were sought who discuss teacher training, especially those who teach Mathematics, playfulness and LEM, in their different perspectives, they were: Brougère (2002), Gatti (2019), Shulman (2005), Lorenzato (2010), Silva (2014, 2020a, 2020b), Cury (2011) and Alves (2001). The research signaled a recognition of LEM as an important space for initial training and future teaching practice. However, the participants were not guaranteed immersion in that space during the degree course.

Conceptions. Teacher training. Degree in Mathematics. Mathematics Education Laboratory.
\end{abstract}

Os autores cedem à Revista Internacional Educon os direitos de primeira publicação do presente artigo. Aplicam-se os termos de uma licença Creative Commons Atribuição 4.0 Internacional (CC BY 4.0), que permite o uso irrestrito, a distribuição e a reprodução em qualquer meio desde que a publicação original seja corretamente citada. 


\begin{abstract}
RESUMEN: Este articulo es el resultado de una investigación cualitativa del tipo estudio de caso que tuvo como objetivo comprender qué concepciones presentan los estudiantes de un curso de Grado en Matemáticas, en su último semestre del curso, en relación con el Laboratorio de Educación en Matemáticas (LEM) y sus implicaciones para su formación y futura práctica profesional. Para la producción de datos, se utilizó un cuestionario, con preguntas abiertas, que fueron analizadas por Content Analysis, refiriéndose, sobre todo, a Bardin (2009). Para la base teórica, se buscaron autores que discutan la formación del profesorado, especialmente aquellos que enseñan Matemáticas, lúdico y LEM, en sus diferentes perspectivas, fueron: Brougère (2002), Gatti (2019), Shulman (2005), Lorenzato (2010), Silva (2014, 2020a, 2020b), Cury (2011) y Alves (2001). La investigación señaló un reconocimiento de LEM como un espacio importante para la formación inicial y la práctica docente futura. Sin embargo, a los participantes no se les garantizó la inmersión en ese espacio durante la carrera de grado.
\end{abstract}

Concepciones. Formación de profesores. Laboratorio de Educación Matemática. Graduación en Matemáticas.

\title{
Introdução
}

Diante do atual cenário educacional, permeado por constantes mudanças demandadas pela contemporaneidade, o processo de formação de professores é constantemente questionado, sobretudo, pela distância que há entre essa formação e as diversas realidades brasileiras. Como destacaram Gatti (2010) e Gatti, Barreto, André e Almeida (2019) a partir de pesquisas realizadas nos últimos 20 anos, muitos cursos de licenciatura configuram-se excessivamente teóricos, em uma construção curricular que se aproxima, muitas vezes, de um bacharelado.

O que apresentamos no parágrafo anterior nos provoca a pensar: como formar professores sem articular essa formação estritamente com o contexto da Educação Básica, espaço de futura atuação profissional? Sabemos que esse distanciar, presente em muitos cursos, impacta o processo de constituição da identidade docente. Isso, de certa forma, acontece em algumas licenciaturas em Matemática, como destacou Santos (2002).

Os professores que ensinam Matemática no Brasil encontram uma realidade de aprendizagem permeada por grandes dificuldades, como sinalizado pelas inúmeras avaliações externas e, também, pelas avaliações internas. Muitos estudantes da Educação Básica percebem a Matemática, como apontou D’Ambrosio e D’Ambrosio (2006), como uma ciência difícil e descontextualizada das situações cotidianas. Ao professor, ainda segundo os autores anteriormente referenciados, resta um importante desafio em busca de uma educação matemática verdadeiramente de qualidade: desconstruir essa imagem.

Sabemos, partindo do que destacou Silva (2020a), que as dificuldades que apontamos anteriormente resultam de uma série de problemáticas que historicamente foram postas e que se relacionam diretamente, além do movimento de formação de professores que ensinam Matemática no país. Muitos cursos, ainda segundo o autor, apresentavam um modelo de formação que hierarquizava os conhecimentos necessários à docência colocando em desprivilegio alguns desses conhecimentos.

Para desmistificar a imagem que a Matemática possui de difícil e descontextualizada da vida cotidiana, e assumir o desafio de mudar essa realidade quanto aos processos de ensino e aprendizagem dessa ciência, as estratégias metodológicas e o uso de recursos lúdico-manipulativos podem contribuir muito positivamente, como sinalizou Silva (2014). Tais estratégias e recursos precisam ser bem apresentados, articulados ao contexto da Educação Básica, ainda durante a formação inicial do futuro professor.

Nesse ínterim, percebendo o Conhecimento Lúdico e Lúdico e Pedagógico do Conteúdo (CLPEC) (SILVA, 2020b, no prelo), enquanto necessários à sua formação inicial e futura prática pedagógica, alguns cursos de licenciatura em Matemática fazem uso de um espaço importante nesse processo de formação do professor: o Laboratório de Educação Matemática (LEM). Os LEM, como são conhecidos, são espaços presentes nas universidades e escolas, que reúnem materiais didáticos diversos, como jogos, brincadeiras, material dourado, áudio de músicas com conteúdos matemáticos, livros 
didáticos, softwares etc. (LORENZATO, 2010). Neles, segundo Silva (2014), os futuros professores podem vivenciar e (re)pensar o ensino na perspectiva de contribuir para uma aprendizagem na qual o aluno compreenda e torne aplicável ao dia a dia, quando possível, os conceitos estudados.

Para isso, portanto, é necessário que o professor que ensina Matemática tenha uma formação adequada, possibilitando a utilização desse espaço e, como asseverou Silva (2014), das diferentes metodologias de ensino, principalmente no tocante às questões de criatividade que permeiam toda a sua utilização. Por isso, diante de tudo que apresentamos até aqui, temos como perguntas de pesquisa: Como estudantes do curso de licenciatura em Matemática concebem o LEM? Como esse espaço foi apresentado durante o seu processo de formação inicial? Qual(is) a(s) influência(s) do trabalho realizado nesse espaço para as suas formações?

Nesse sentido, portanto, destacamos como objetivo desta pesquisa: compreender quais as concepções que estudantes do curso de licenciatura em Matemática da Universidade do Estado da Bahia (UNEB), Campus VII, apresentam, em seu último semestre do curso, em relação ao Laboratório de Educação Matemática e as implicações do mesmo para as suas formações e futura prática profissional.

Esta pesquisa vincula-se ao Laboratório de Estudos e Pesquisas em Educação Matemática, um espaço de formação do [futuro] professor de Matemática inserido na Universidade do Estado da Bahia (UNEB), Campus VII, em Senhor do Bonfim, que busca por meio de estudos e pesquisas, bem como de atividades extensionistas, contribuir com o processo de construção da identidade docente. Todos os trabalhos desenvolvidos nesse espaço visam ampliar o olhar acerca das inúmeras problemáticas postas pela Educação Básica quanto ao processo de ensino e aprendizagem da Matemática.

Este artigo está dividido em quatro seções: i) a introdução, onde contextualizamos a temática pesquisada e apresentamos as questões e os objetivos que nortearam esta pesquisa; ii) o percurso metodológico, onde classificaremos a pesquisa e os instrumentos de produção de dados, bem como os procedimentos de análise; iii) a apresentação e a análise dos dados, onde discutiremos, articuladamente a produção teórica realizada e os conteúdos produzidos pelos participantes; e por último iv) a exposição de algumas considerações de fim de texto.

\section{Percurso Metodológico}

A priori, é importante salientar, partindo do que destacou Silva e Oliveira (2020), que entendemos necessário, neste percurso de formação do futuro professor que ensina Matemática, discutir e trabalhar a sala de aula como importante espaço de investigação e formação, rompendo com toda a lógica tradicional de pesquisa que a desconsidera, bem como o envolvimento do pesquisador com os pesquisados. Para desenvolver o perfil de um professor pesquisador de sua própria prática, algo necessário na formação inicial, cabe ao [futuro] docente entender o seu lugar na pesquisa e o seu vínculo com os demais participantes como importantes, contrariando os modelos mais tradicionais de investigação.

De fato, a investigação construída pelo próprio professor torna a sua prática objeto de pesquisa, o que permite um movimento de reflexão sobre a sua ação em sala de aula ou outros espaços de formação, como o Laboratório de Educação Matemática. Dessa estreita relação estabelecida entre a sala de aula (ou LEM), o professor e os estudantes, o pesquisador protagoniza a busca por respostas para as inúmeras inquietudes cotidianas que circunscreve a sua prática docente. Em outras palavras: a pesquisa, resultada de demandas percebidas pelo professor em ação, transforma profundamente a sua própria prática através da ação-reflexão-ação (SILVA, 2014).

Nesse sentido, partindo da atuação do autor deste texto de pesquisa no espaço de formação inicial de professores que ensinam Matemática, sobretudo em Laboratórios de Educação Matemática, propomos, para este trabalho, uma investigação qualitativa, do tipo pesquisa de campo, por entendê-la como a mais apropriada para ampliar o olhar acerca do objetivado com esse estudo (GIL, 2012).

Nesse sentido, a referida pesquisa foi realizada no Campus VII da Universidade do Estado da Bahia, em Senhor do Bonfim. Cabe destacar que essa instituição possui um espaço de Laboratório, nomeado atualmente como Laboratório de Estudos e Pesquisas em Educação Matemática (LEPEM), e 
foi partindo das diversas práticas realizadas nesse espaço e no desejo de aprimorá-las que essa investigação foi desenvolvida.

Participaram desse estudo, realizado no ano de 2019, além do pesquisador e autor deste texto de pesquisa, nove estudantes da licenciatura em Matemática da UNEB, Campus VII, matriculados em seu último semestre do curso. Vale destacar que todas as questões éticas foram respeitadas e os estudantes que aceitaram participar voluntariamente assinaram o Termo de Consentimento Livre e Esclarecido (TCLE). Tendo em vista manter o anonimato dos sujeitos da pesquisa, os chamaremos por nomes fictícios.

Para produção de dados, tendo em vista ampliar o olhar acerca do objetivado com essa investigação (compreender quais concepções os estudantes do curso de licenciatura em Matemática da UNEB apresentam em relação ao Laboratório de Educação Matemática e as implicações do mesmo para as suas formações e futura prática profissional), utilizou-se um questionário contendo sete questões abertas. Foram elas: 1) $\mathrm{Na}$ instituição que você faz sua licenciatura em Matemática possuí algum Laboratório de Educação Matemática?; 2) O que é o Laboratório de Educação Matemática para você?; 3) $\mathrm{O}$ que deve ter em um espaço como esse?; 4) Em quais momentos do curso você usou esse espaço e com que finalidade?; 5) Para a sua formação e futura prática como professor de Matemática, qual foi a influência do trabalho realizado no LEM?; 6) Nas escolas em que realizou o estágio, por exemplo, tinha LEM?; 7) Você considera esse um espaço de formação importante para as licenciaturas em Matemática? Comente.

Entendemos, nesse momento, fundamentando-nos em Cury (1999, p. 37), que as concepções são conjuntos de ideias, construídas a partir das experiências que as pessoas tiveram e "do conhecimento que construíram, das opiniões de seus mestres, enfim, das influências socioculturais que sofreram durante suas vidas, influências essas que se vêm formando ao longo dos séculos, passando de geração a geração $[\ldots] "$.

Tendo em vista os conteúdos produzidos pelos estudantes concluintes do curso que participaram da pesquisa, a partir das respostas apresentadas no questionário, optamos pelo método da Análise de Conteúdo (AC), que consiste num conjunto de técnicas de análise das comunicações que faz uso de procedimentos sistemáticos e objetivos de descrição do conteúdo da mensagem. Vale destacar que, a AC organiza-se em torno de três polos: 1. A pré-análise; 2. A exploração do material; e 3. O tratamento dos resultados: a inferência e a interpretação (BARDIN, 2009, p. 121).

\section{Um Olhar Teorizado Para Os Dados Produzidos}

Nesta seção, partindo do caminhar metodológico apresentado anteriormente, faremos a análise dos dados produzidos pelos participantes a partir das respostas apresentadas às questões presentes no questionário de pesquisa. Optamos por apresentar uma seção de discussão teórica articuladamente aos dados produzidos. Consideramos que esse movimento de discussão teórica, partindo dos dados empíricos, sinaliza o que de fato deve ser aprofundado e discutido teoricamente.

Seguindo as etapas apresentadas por Bardin (2009) para a realização da AC, sobretudo a etapa inicial de pré-análise dos conteúdos produzidos nos questionários dos participantes, estabelecemos duas categorias de análise, são elas: i) O que é o Laboratório de Educação Matemática? e ii) Como o trabalho realizado nesse espaço influenciou minha formação e futura prática com a Matemática? A seguir, apresentaremos os resultados das demais etapas de exploração do material e do tratamento e interpretação dos resultados.

\subsection{O Que É O Laboratório De Educação Matemática?}


Para iniciar esta seção, pensamos ser pertinente retomar a concepção de LEM que apresentamos na introdução deste texto e, ampliá-la a partir das respostas apresentadas pelos participantes da pesquisa. Como dissemos na introdução, os Laboratórios de Educação Matemática, como são comumente conhecidos, são espaços presentes nas universidades e escolas, que reúnem materiais didáticos diversos. Neles, se vivencia e (re)pensa o ensino de Matemática em uma perspectiva que contribua para uma aprendizagem com significado dos conceitos matemáticos estudados.

Nessa direção, portanto, os LEM são importantes espaços de formação inicial por, como já dissemos ao longo do texto, concordando com o que destacaram Lorenzato (2010), Silva (2014) e Silva (2020b), possibilitar a aproximação do futuro docente com as diferentes realidades de ensino e aprendizagem da Matemática. Nesse lugar, é possível conhecer diferentes materiais didáticos e, partindo de situações como as de estágio supervisionado, ou de outras situações reais de inserção nas salas de aula da Educação Básica, constituir diferentes conhecimentos necessários à docência, como o conhecimento pedagógico do conteúdo (SHULMAN, 2005).

Partindo da percepção desse espaço de formação como importante, questionamos os participantes da pesquisa sobre a existência do Laboratório de Educação Matemática na instituição que cursam a licenciatura. Percebemos, nas respostas apresentadas, que todos sinalizam positivamente quanto a sua existência e, de alguma forma, destacaram terem o visitado. Alicia, por exemplo, destaca que o espaço do LEM era usado como sala de aula e que já o visitou. Daniel, indo ao encontro do que apresentou Alicia, sinaliza que visitou o espaço, mas que nunca utilizou/manipulou os materiais disponibilizados.

Para aprofundar melhor sobre como se deu essas visitas ao longo do curso, uma vez que foi unânime que elas aconteceram de diferentes formas, pelos partícipes da pesquisa, os questionamos sobre em quais momentos do curso utilizaram o espaço e com que finalidade. Observemos o que responderam os estudantes.

\footnotetext{
"Utilizei apenas como espaço de reunião com finalidades que não estavam relacionadas ao papel de formação do laboratório” (LAURA, 2019, destaques nossos).

"Durante as disciplinas de Matemática Financeira e Cálculo III, pois não havia salas disponiveis para a execução das mesmas" (CIRILO, 2019, destaque nosso).

"Nas aulas de Cálculo, pois os professores estavam sem sala para dar aula" (MARCELINA, 2019, destaque nosso).

"Poucas vezes para assistir aulas" (ALICIA, 2019, destaque nosso).

"Nunca foi utilizado" (MARIA JOAQUINA, 2019, destaque nosso).

“Nunca usel” (DANIEL, 2019, destaque nosso).
}

Fica evidente, nas respostas apresentadas pelos participantes: Laura, Cirilo, Marcelina e Alicia, que o espaço do Laboratório de Educação Matemática era usado como suporte para as situações em que não "havia salas disponíveis" ou como "espaço de reunião". Como destacou Laura, as atividades desenvolvidas no LEM "não estavam relacionadas ao papel de formação do laboratório". Diferentemente desses participantes, que referenciamos anteriormente, Jorge e Renê tiveram outras experiências. Vejamos:

"Durante o Estágio Supervisionado III, com a finalidade de construir materiais didáticos para vivência de uma oficina. Além disso, desenvolvi atividades de estágio durante o último semestre do curso" (JORGE, 2019, destaque nosso).

"Utilizei durante o componente curricular Laboratório de Matemática. A principal finalidade foi criar objetos matemáticos para aplicação na sala de aula da Educação Básica” (RENÊ, 2019, destaque nosso). 
Para Jorge e Renê, o LEM ocupou um lugar de formação, como o que era esperado por Alicia, "de construir materiais didáticos para vivência de uma oficina". Percebemos que esses dois estudantes participaram de atividades que permitiram, concordando com o que destacaram Silva (2014) e Lorenzato (2010), pensar a criação de "objetos matemáticos para a aplicação na sala de aula da Educação Básica". Nessa direção, vejamos as concepções que os participantes da pesquisa apresentaram sobre esse espaço. Jorge, Laura e Alicia destacam que:

\footnotetext{
"Não é apenas um lugar onde se guarda materiais, é um espaço de formação que contribui para o desenvolvimento de práticas e experiências que são importantes para os futuros docentes" (JORGE, 2019, destaque nosso).

"Penso que seja um ambiente onde existam objetos metodológicos para facilitar o ensino de Matemática, onde acontecem estudos sobre práticas metodológicas para o ensino de Matemática” (CIRILO, 2019, destaque nosso).

"Espaço útil na formação de professores" (LAURA, 2019, destaque nosso).

"Um espaço para se trabalhar o ensino da Matemática" (ALICIA, 2019, destaque nosso).
}

Observemos, partindo do que apresentaram os respondentes, que existe um reconhecer do LEM enquanto espaço "de formação que contribui para o desenvolvimento de práticas e experiências que são importantes para os futuros docentes". Há ainda, na fala de Jorge, concordando com o que apresentou Lorenzato (2010) e Turrioni e Perez (2010), o avançar no entendimento desse espaço como mais que um “depósito de materiais". Pelo contrário, pelas respostas apresentadas entendemos o LEM como espaço dinâmico de formação, tanto para os futuros professores como para os seus futuros estudantes da Educação Básica. Nesse espaço, como trouxe Alicia, se "trabalha o ensino de Matemática” e para esse trabalho é importante saber como esses materiais funcionam e qual o papel que cada um ocupa nos processos de ensino e aprendizagem.

O trabalho a que Alicia se referiu em sua resposta nos remete a uma discussão extremamente necessária: o estabelecimento de relações entre o material didático e o objeto matemático. Pegaremos o uso de jogos como exemplificação. Segundo Brougère (2002, p. 6) "pensar as relações entre jogo e educação é mais complexo do que parece". Isso, em nosso entendimento, só é possível para um profissional que tenha uma formação adequada.

Nessa direção, retomando as questões envoltas ao ensino de Matemática, Alves (2001) apresentou essa ciência como uma das áreas mais caóticas em termos da compreensão dos conceitos. Por isso, ainda segundo o que apresentou a autora, o uso de materiais didáticos diversos, se apresentaria como auxílio na compreensão para muitas estruturas matemáticas complexas. Utilizar diferentes estratégias e recursos seria, como sinalizou Silva (2014), uma possibilidade proporcionada ao discente da Educação Básica, de estabelecer relações entre os conceitos apresentados e o seu cotidiano. Para isso, é importante conhecer com profundidade esses materiais em um movimento de inserção nas diferentes realidades educacionais. $\mathrm{Na}$ direção dessa discussão, vejamos o que responderam Maria Joaquina, Marcelina e Daniel.

"É um espaço de construção de conbecimento, em que os professores podem levar seus alunos, dinamizando o conteúdo, e enriquecendo as atividades de ensino e aprendizagem" (MARIA JOAQUINA, 2019, destaques nossos).

"Na minha concepção, o Laboratório de Educação Matemática é um espaço destinado para dar suporte à realização de atividades com o uso de materiais didáticos, possibilitando um melhor processo de ensino e aprendiragem da Matemática" (MARCELINA, 2019, destaque nosso). 
"Um ambiente com materiais que talvez. auxilie nas explicações de conteúdos um pouco abstrato" (DANIEL, 2019, destaque nosso).

Partindo dos excertos apresentados anteriormente e concordando com o que destacaram Rêgo e Rêgo (2010) e Lorenzato (2010), o LEM precisa ser percebido como espaço para se trabalhar com diversos materiais didáticos e onde se proporciona ao discente da Educação Básica, a possibilidade de estabelecer relações entre os conceitos apresentados pelo professor e o seu cotidiano. Não se trata de um espaço exclusivo da Universidade, pelo contrário, é importante a sua presença dentro das escolas para auxiliar o trabalho dos professores que ensinam Matemática. Percebemos, nesse momento, como destacaram Civardi (2011) e Varizo (2011), uma relação importante que intercruza o LEM enquanto espaço colaborativo de formação, tendo os processos de ensino e aprendizagem da Matemática como objeto principal de trabalho.

Para respaldar teoricamente essa questão, utilizaremos a fala de Lorenzato (2010), que define o LEM como "um local para criação e desenvolvimento de atividades experimentais, inclusive de produção de materiais instrucionais que possam facilitar o aprimoramento da prática pedagógica" (LORENZATO, 2010, p. 6). O LEM, portanto, precisa ser percebido como "o centro da vida matemática da escola" (LORENZATO, 2010, p. 6). Nesse sentido, portanto, vejamos o que responderam Carmen e Renê.

"É um lugar onde tem recursos pedagógicos que visam permitir aos professores tornar as suas aulas mais didáticas. É um lugar que professores e alunos podem expandir sua criatividade" (CARMEN, 2019, destaque nosso).

"É essencial para formação do professor de Matemática, pois possibilita o desenvolvimento de atividades para as práticas de ensino na sala de aula. As atividades do Laboratório de Educação Matemática possibilitam pesquisar estratégias de ensino dos conteúdos matemáticos de forma lúdica" (RENÊ, 2019, destaque nosso).

Nos excertos apresentados anteriormente percebemos que duas categorias são apresentadas como resultado do trabalho no LEM: expandir a criatividade e perceber os conteúdos matemáticos ludicamente. Embora seja possível fazer algumas aproximações entre essas duas categorias (ludicidade e criatividade) é importante sinalizá-las enquanto diferentes. Para isso, portanto, faremos uma análise etimológica.

A palavra "lúdico", como apontaram Santos e Cruz (2011, p. 9), vem do latim ludus e significa brincar. Inclui-se nesse brincar os jogos, brinquedos e divertimentos, e ainda a conduta daquele que joga, que brinca e que se diverte.

Já a etimologia da palavra "criatividade" nos remete ao termo criar, do latim creare que significa, como nos apresenta Pereira, Mussi e Knabben (1999, p. 4), "dar existência, sair do nada, estabelecer relações até então não estabelecidas pelo universo do indivíduo, visando determinados fins". Percebemos, por esse olhar ao que significa cada um dos termos, que se trata de duas coisas diferentes.

Nesse sentido, cabe-nos apresentar algumas pré-categorias que podem ser levantadas para evidenciar as questões de ludicidade dentro do espaço do LEM. Portanto, para que as atividades propostas no espaço do laboratório sejam tomadas pelos estudantes como lúdicas, cabe observar se existe liberdade, interesse, prazer, diversão, alegria e bem-estar na participação. É preciso garantir e valorizar as diferentes formas de matematizar (SILVA, 2014).

Vale pontuar, ainda de acordo com Silva (2014), que as questões levantadas referem-se tanto ao trabalho do Laboratório de Educação Matemática, no movimento propiciado pela formação docente, como ao trabalho de ensino e aprendizagem da Matemática com os estudantes da Educação Básica. Tendo em vista essas duas questões, apresenta-se outra pré-categoria, que é o de criação, sem medo de errar, e o de tornar a Matemática compreensível.

Segundo Kamii e DeVries (2009, p. 18), "assim como cada criança tem que reinventar o conhecimento para dele se apropriar, cada professor precisará construir sua maneira própria de 
trabalhar"; só assim ocorrerá a “desadaptação criativa” (FERNÁNDEZ, 2001, p. 43), ou seja, ao invés de o sujeito adaptar-se à realidade, ele precisa desadaptar o pensamento, a criatividade e a inteligência. Esse processo de desadaptação criativa pode ser visto como a possibilidade de o sujeito, por sua própria estrutura lógica, desconstruir e construir as suas concepções, o que resulta em um processo de ensinoaprendizagem autônomo. O LEM permite que isso aconteça e que aconteça, sobretudo, a partir do princípio da ludicidade, ou seja, com prazer pelo que se faz.

\subsection{Como O Trabalho Realizado Nesse Espaço Influenciou Minha Formação E Futura Prática Com A Matemática?}

Partindo das discussões empreendidas na seção anterior, quando os respondentes foram questionados sobre o que concebem por Laboratório de Educação Matemática, fica evidente que há um reconhecimento dos particpantes da pesquisa de que o LEM é um espaço importante para as suas formações iniciais e futuras práticas docentes. No entanto, quando questionados sobre como o trabalho realizado nesse espaço influenciou as suas formações e futura prática com a Matemática, sinalizam que

"Nenbuma. Pois não usufruimos de nada e nem foi ensinado nada sobre o que ele continha e sua finalidade" (CIRILO, 2019, destaque nosso).

“Não Recordo de ter usado o LEM”' (LAURA, 2019, destaque nosso).

"Nenhuma” (MARCELINA, 2019, destaque nosso).

“Nenhuma, porque nunca utilizei" (DANIEL, 2019, destaque nosso).

"Nenbuma" (CARMEN, 2019, destaque nosso).

"Sendo bem verdadeira: nenbuma" (ALICIA, 2019, destaque nosso).

"A construção de alguns materiais didáticos, como atividades dos componentes Laboratório do Ensino I e II. Talvez a falta de equipamentos fez com que os professores não utilizassem esse espaço com mais frequência. Dessa forma, o mesmo não teve muita influência na minha formação" (JORGE, 2019, destaque nosso).

"Na minha formação, infelizmente, a influência foi pouca devido à falta de professores capacitados que possibilitassem atividades práticas no Laboratório de Matemática. Eu só utilizava o Laboratório de Matemática para monitoria, mas sem fazer uso dos objetos do laboratório, pois boa parte desses objetos estava ultrapassada ou eram inadequados para o ensino da Matemática” (RENÊ, 2019, destaque nosso).

A partir do que responderam os participantes da pesquisa, identificamos que, embora a universidade possuísse um Laboratório de Educação Matemática, o mesmo não era explorado, para a maioria, pelo menos, como parte do movimento de formação e aproximação com as escolas da Educação Básica.

Dessa forma, tendo em vista a não imersão dos respondentes nesse espaço, ao longo do curso, eles não conseguem perceber diretamente a influência para as suas formações ou futuras práticas. Mesmo sabendo o que é esse espaço e reconhecendo a sua existência, não foram promovidas nele experiências que contribuíssem na constituição dos conhecimentos necessários à docência. 
Jorge, em sua resposta, destaca que participou de um movimento de produção de material didático durante os componentes curriculares de Laboratório do Ensino de Matemática I e II. Esses componentes, em suas ementas, como destaca Bahia (2011), responsabilizam-se em apresentar e discutir

... situações-problemas do processo de ensino-aprendizagem da Matemática no Ensino Fundamental, diagnosticadas a partir de práticas da sala de aula, tendo como suporte teórico os pressupostos da Educação Matemática. Analisa, discute e elabora propostas de planejamento, avaliação, recursos didáticos e outros instrumentos de intervenção no processo de ensinoaprendizagem da Matemática, neste segmento de ensino (BAHIA, 2011, p. 193).

O curioso é que nem todos os estudantes significaram o trabalho com esses componentes dessa forma. A maioria dos estudantes, pelo contrário, não conseguiram perceber influências do LEM para as suas formações e futura prática. Isso, muitas vezes, se deve pela forma como os componentes curriculares são significados. Embora a ementa seja clara quanto às práticas de sala de aula, a elaboração de propostas de intervenção e criação de recursos didáticos, pode se dar em outros espaços, como a sala de aula da universidade, mesmo a universidade tendo um LEM.

Decidimos, portanto, questioná-los sobre que tipo de materiais esse espaço de formação deve ter. Vejamos o que responderam:

“Recursos que favoreçam o ensino e aprendizagem” (LAURA, 2019).

"Todos os materiais que podem ser utilizados para o ensino-aprendizagem de Matemática, exemplos: materiais didáticos, jogos matemáticos, instrumentos construídos pelos discentes, etc." (JORGE, 2019).

"Material dourado; computador; objetos de simulação de compra e venda (feira, por exemplo, para auxiliar no ensino das quatro operações fundamentais); ábaco, etc.” (CIRILO, 2019).

“Jogos Matemáticos” (MARCELINA, 2019).

“Computadores, jogos e livros" (ALICIA, 2019).

"Os materiais de pesquisa como computadores, placas de arduínos para robótica, sólidos geométricos, matérias algébricos, etc.” (RENÊ, 2019).

"Mesas com cadeiras, computador, quadro branco, estante, jogos matemáticos, materiais geométricos, materiais lúdicos e etc.” (MARIA JOAQUINA, 2019).

"Objetos com representação de figuras geométricas (planas e espaciais). Objetos construídos a partir de aulas práticas, etc.” (DANIEL, 2019).

Materiais concretos envolvendo a Matemática (CARMEN, 2019).

Fica visível, com as respostas apresentadas, que tipo de recurso é esperado encontrar nesse espaço. A apresentação desses diversos materiais sinaliza o tipo de formação que se espera: uma que relacione a Matemática com as diversas situações cotidianas e materiais lúdico-manipulativos, desde os materiais físicos aos tecnológicos. Para além dos materiais industrializados, Daniel destaca a necessidade de materiais construídos pelo grupo. Nessa direção, importante considerar o que destacou Silva (2020b), sobre a imersão em escolas da Educação Básica para a construção ou adaptação de materiais que atendam as necessidades e expectativas de aprendizagem da turma. Esse é, ainda segundo o autor, um movimento complexo e que, para isso, o LEM cumpre um importante papel. 
Embora reconhecendo a importância que o LEM ocupa nos movimentos de ensino e aprendizagem da Matemática, sobretudo para a Educação Básica, todos os participantes destacaram que nas escolas em que desenvolveram os estágios supervisionados, ao longo do curso, não existiam laboratórios desse tipo. Alguns estudantes revelam em suas respostas a grande dificuldade em encontrar materiais que os apoiem no processo de ensino da Matemática.

Ainda em relação ao que discutimos anteriormente, Jorge sinaliza que "a utilização dos materiais existentes no laboratório podem auxiliar no trabalho com os conteúdos”. Segundo o estudante, pelo percebido na continuidade de sua resposta, o LEM da universidade precisa disponibilizar materiais que ajudem os estudantes estagiários, por exemplo, no momento de planejamento e vivência de suas aulas. A construção de materiais didáticos, ainda segundo Jorge, é uma atividade de formação indispensável para esse espaço por contribuir para as futuras práticas a serem desenvolvidas no exercício profissional. Todos os participantes, portanto, consideram o LEM um espaço importante para a formação, e isso foi posto textualmente.

\section{Considerações finais}

Este artigo, resultado de uma investigação qualitativa do tipo estudo de caso, buscou ampliar o olhar acerca das seguintes perguntas de pesquisa: Como estudantes do curso de licenciatura em Matemática concebem o LEM? Como esse espaço foi apresentado durante o seu processo de formação inicial? Qual(is) a(s) influência(s) do trabalho realizado nesse espaço para as suas formações?

Nesse sentido, pela própria natureza da pesquisa realizada, busca-se pelo movimento da própria investigação, aprimorar o trabalho realizado no Laboratório de Educação Matemática da Universidade, contribuindo para a formação dos futuros professores e, consequentemente, para os processos de ensino e aprendizagem da Matemática. Precisamos considerar que só descobrimos a natureza de algumas coisas quando tentamos mudá-las.

Embora o autor do texto tenha assumido apenas em 2019 o trabalho com o LEPEM da UNEB, faz-se pertinente saber o que os estudantes do curso percebem por esse espaço e como o trabalho estava sendo desenvolvido. Isso, de certa forma, permite um movimento de planejamento e ação que, tendo como base a realidade da comunidade acadêmica, significa a formação dos professores que ensinam Matemática, formados pelo Campus VII da universidade. É importante atender as demandas que são postas pelos próprios participantes da pesquisa.

Nesse sentido, portanto, tendo em vista as perguntas que nortearam a escrita deste texto de pesquisa, consideramos que os estudantes concluintes percebem o LEM como um espaço de formação inicial importante e, além disso, necessário para a futura prática docente. Reconhecem-no enquanto lugar que pode contribuir para o movimento de matematizar e para a construção da criatividade e ludicidade. O "chão da sala de aula" e as diferentes realidades educacionais precisam ser considerados para as suas atividades.

Portanto, para que o LEM cumpra o seu papel de formação é necessário que a universidade, em seu espaço colegiado de curso, assuma o compromisso de estabelecer as relações necessárias com a Educação Básica e com a promoção de atividades que insiram os futuros professores nas diferentes práticas desenvolvidas. Um ponto destacado pelo estudo é a necessidade de que, ao longo da licenciatura, os estudantes conheçam o LEM e, acima de tudo, que ele faça parte das diferentes práticas que acontecem no curso.

\section{Referências}

Alves, E. M. S. (2001). A ludicidade e o ensino da matemática: uma prática possível. Campinas, SP: Papirus. 
Bahia. (2011). Projeto Pedagógico do Curso de Licenciatura em Matemática da Universidade do Estado da Bahia, Campus VII. Senhor do Bonfim: Universidade do Estado da Bahia.

Bardin, L. (2009). Análise de conteúdo. Lisboa, Portugal; Edições 70, LDA.

Brougère, G. (2002). Lúdico e educação: novas perspectivas. In Revista Linhas Críticas, Brasília. v. 8, n. $14,5-20$.

Civardi, J. A. (2011). A concepção e o papel do laboratório de educação matemática no curso de licenciatura: primeiras reflexões. In VARIZO, Z. C. M; CIVARDI, J. A. (Org.). Olhares e reflexões acerca de concepções e práticas no laboratório de educação matemática. Curitiba, PR: CRV, 8-13.

Cury, H. N. (1999). Concepções e crenças dos professores de matemática: pesquisas realizadas e significado dos termos utilizados. In Bolema. Boletim de Educação Matemática (UNESP. Rio Claro. Impresso), Rio Claro, 29-43. Recuperado em 16 julho, 2020, de http://www.periodicos.rc.biblioteca.unesp.br/index.php/bolema/article/view/10640.

D’ambrósio, B \& S; D’ambrósio, U. (2006). Formação de professores de matemática: professorpesquisador. Atos de pesquisa em educação, v. 1, n. 1, 2006, 75-85.

Fernández, A. (2001). O Saber em jogo: a psicopedagogia propiciando autorias de pensamento. Tradução de Neusa Kern Hickel. Porto Alegre: Artmed.

Gatti, B. (2010). Formação de professores no Brasil: características e problemas. Educação e Sociedade, Campinas, v. 31, n. 113, 1355-1379.

Gatti, B. A; Barreto, E. S. S; André, M. E. D. A \& Almeida, P. C. A. (2019). Professores no Brasil: novos cenários de formação. Brasília: UNESCO.

Gil, A. C. (2012). Métodos e técnicas de pesquisa social. 5. ed. São Paulo: Atlas.

Kamii, C; Devries, R. (2009). Jogos em grupo na educação infantil: implicações da teoria de Piaget; Prefácio Jean Piaget. Tradução Marina Célia Dias Carrasqueira. ed. rev. Porto Alegre. Artmed.

Lorezanto, S. (2010). O laboratório de ensino de matemática na formação de professores. 3. ed. (Coleção formação de professores). Campinas, SP: Autores associados.

Pereira, B.; Mussi \& C.; Knabben, A. (1999). Se sua empresa tiver um diferencial competitivo, então comece a recriá-lo: a influência da criatividade para o sucesso estratégico organizacional. In Anais do XXII ENANPAD. Foz do Iguaçu: ANPAD.

Rêgo, R. M. do \& RÊGO, R. G. do. (2010). Desenvolvimento e uso de materiais didáticos no ensino da matemática. In Lorenzato, S. (Org.) O Laboratório de Ensino de matemática na Formação de Professores. Campinas - SP: Autores Associados, 39-56.

Santos, S. M. P \& Cruz. D. R. M. O. (2011). O lúdico na formação do educador. 9ª ed. Petrópolis: Vozes. 
SANTOS, V. M. (2002). O Desafio de Tornar-se Professor de Matemática. In Nuances: estudos sobre educação. ano VIII, n. 08. Recuperado em 21 abril, 2020, de https://revista.fct.unesp.br/.

Shulman, L. S. (2005). Conocimiento y enseñanza: fundamentos de la nueva reforma. Profesorado. In Revista de Currículum y formación del profesorado, v. 9, n. 2, 1-30. Recuperado em 15 maio, 2020, de http://www.ugr.es/ recfpro/Rev92.html.

Silva, A. J. N. (2014). A ludicidade no laboratório: considerações sobre a formação do futuro professor de matemática. Curitiba: Editora CRV.

Silva, A. J. N. Da. (2020a). Um revisitar as memórias educacionais: os primeiros cursos de Matemática e as implicações para a formação do professor. In SILVA, A. J. N. da S. (Org.). Museu Pedagógico e Memória Educacional. 1ed. Ponta Grossa: Atena Editora, v. 1, 22-36. Recuperado em 16 junho, 2020, de https://www.atenaeditora.com.br/post-ebook/3299.

Silva, A. J. N. Da. (2020b). Laboratório de Estudos e Pesquisas em Educação Matemática do campus VII da UNEB: espaço de formação e desenvolvimento do conhecimento lúdico e pedagógico do conteúdo. In Vieira, A. R. L; Silva, A. J. N. O futuro professor de Matemática: vivências que intercruzam a formação inicial. Ponta Grossa: Editora Fi. no prelo.

Silva, A. J. N. \& Oliveira, C. M. (2020). A pesquisa na formação do professor de Matemática. In Revista Internacional de Formação de Professores (RIPF), v. 5, p. 1/ e020015-23.

Turrioni, A. M. S \& Perez, G. (2010). Implementando um laboratório de educação matemática para apoio na formação de professores. In Lorenzato, S. (Org.). O laboratório de matemática na Formação dos Professores. Campinas: Autores Associados, 57-76.

Varizo, Z. C. M. (2011). Concepção e implementação de um laboratório de Educação matemática no Ensino Superior. In Varizo, Z. C. M; Civardi, J. A. Olhares e reflexões acerca de concepções e práticas no laboratório de educação matemática. Curitiba, PR: CRV, 21-42. 


\section{Sobre o Autor:}

\section{AMÉRICO JUNIOR NUNES DA SILVA}

(D) ORCID: https://orcid.org/0000-0002-7283-0367

Doutor em Educação pela Universidade Federal de São Carlos (UFSCar). Professor do Departamento de Educação da Universidade do Estado da Bahia (UNEB/Campus VII) e docente permanente do Programa de Pós-Graduação em Educação, Cultura e Territórios Semiáridos (PPGESA/UNEB). Integra o Grupo de Estudos e Pesquisas em Educação Matemática (CNPq/UFSCar), na condição de pesquisador e do Grupo Educação, Desenvolvimento e Profissionalização do Educador (UNEB/PPGESA), na condição de vice-líder. É editor-chefe da Revista Baiana de Educação Matemática (RBEM).

E-mail: ajnunes@,uneb.br

Currículo Lattes: http://lattes.cnpq.br/5104791370402425.

Submetido: 24 jul. 2020

Aceito: 14 ago. 2020 